\title{
LA INVERSIÓN DE LOS EFECTOS DEL SILENCIO EN LA REFORMA PROCESAL CIVIL: "QUIEN CALLA SÍ OTORGA"
}

[The Reversal of the Effects of Silence on the Civil Procedure Reform: "Silence Implies Consent"]

\author{
Jordi Delgado Castro* \\ Universidad de Talca, Chile
}

\begin{abstract}
Resumen
El trabajo aborda una problemática antigua que, atendido el nuevo papel intervencionista del juez en el proceso, puede ser releído de una forma original. Tradicionalmente se ha entendido que en derecho procesal quien calla no otorga, es decir, que el litigante que no se defiende no consiente en las pretensiones de la demanda ni en los hechos alegados en ella. Sin embargo, este axioma pudiere ver cambiado su signo si ponemos una correcta atención a la nueva regulación y, al mismo, tiempo realizamos una correcta lectura de lo que hoy prescribe el Código de Procedimiento Civil.

\section{Palabras Clave \\ Silencio procesal - Aceptación tácita - Rebeldía - Reforma Procesal Civil.}

\begin{abstract}
This work addresses an old issue that, considering the new active role of the judge all through the proceedings, can have a different interpretation. It has traditionally been understood that, in procedural law, silence does not imply consent, this is, the litigant who does not defend himself does not agree on the allegations of the claim or on the facts therein stated. However, the interpretation of this axiom may change if we pay due attention to the new regulation and, at the same time, correctly read what is today stated on the Code of Civil Procedure.

\section{KEYWORDS}

Silence in Civil Procedures - Tacit acceptance - Contempt - Civil Procedural Reform.
\end{abstract}

RECIBIDO el 21 de enero y ACEPTADo el 2 de mayo de 2014

* Profesor de Derecho Procesal de la Facultad de Ciencias Jurídicas y Sociales de la Universidad de Talca. Doctor en Derecho por la Universidad de Barcelona, Dirección electrónica: jdelgado@utalca.cl 


\section{INTRODUCCIÓN}

En las lecciones de Derecho procesal es habitual enfatizar que, al contrario de lo que expresa la sabiduría popular ${ }^{1}$, el que calla no otorga. Sin embargo, a tenor de lo dispuesto en el Proyecto de Código Procesal Civil (= PCPC.) y de una relectura del Código de Procedimiento Civil, pudiera ser que nos encontrásemos ante un cambio en el paradigma del que no hemos visto muchos comentarios en los distintos foros. Es cierto que pudiera tratarse de solamente un equívoco en nuestra hipótesis, pero no lo es menos que los órganos jurisdiccionales quizá encuentren plausible una lectura como la que, en las próximas líneas, vamos a proponer atendida su mayor participación y rol activo en el proceso ${ }^{2}$.

El artículo 272 PCPC. impone la carga general de contravención de las peticiones del actor. Es decir, exige una conducta activa por la que el demandado debe realizar una actuación específica mediante la cual discuta tanto los hechos como los documentos aportados por el demandante. En términos generales, hasta ahora esta circunstancia era la situación ideal en la que se perfeccionaba el periodo de discusión y por lo tanto se justificaba la actuación de un tercero imparcial que resolviera el conflicto.

Ahora bien, la gran revolución, que genera un cambio sustancial en la forma de estudio del proceso civil, es la sanción que contempla esta misma norma. Así, el 272 PCPC. señala, en relación a esta auténtica carga para el demandado que "Su silencio, así como sus afirmaciones ambiguas o evasivas en la contestación podrán ser consideradas por el tribunal como admisión tácita de los hechos que le sean perjudiciales, asi como admisión de la autenticidad, integridad y validez de los documentos acompañados".

De este modo, se nos plantea la pregunta de si efectivamente existe un deber de contravención expreso que pueda generar consecuencias negativas para el demandante que adopta una actitud pasiva o poco contestataria ante la demanda, o bien, en otros términos, si podemos afirmar que en este contexto quien calla pudiera realmente estar otorgando ante la demanda.

${ }^{1}$ Un buen ejemplo de esta afirmación se encuentra desarrollado en el estudio de: Tomas, Gema, Fuentes jurídicas del principio "qui tacet, consintere videtur". Realidad jurídica versus difusión social, en Revue Internationale des Droits de l'Antiquité, 3 (2003), p. 383.

${ }^{2}$ Hunter Ampuero, Iván, Rol y poderes del juez civil: Una mirada desde la eficiencia del proceso, en Revista de Derecho Universidad Católica del Norte, 18 (2011) 2, pp. 73-101. 


\section{ACTITUdES DEL DEMANDADO}

ante la demanda en el "Código de Procedimiento Civil”

Tradicionalmente, se ha expuesto este tema agrupándolo en, a lo menos, dos grandes categorías: la actitud activa y la actitud pasiva ante la notificación de la demanda ${ }^{3}$. En primer lugar, el demandado puede realizar acciones tendientes a defenderse (bien sea mediante la interposición de excepciones ${ }^{4}$, o bien haciendo uso de alegaciones y defensas ${ }^{5}$ ); puede realizar actos destinados a aceptar las peticiones o a admitir determinados hechos ${ }^{6} \mathrm{y}$, en segundo, también puede adoptar una actitud pasiva ${ }^{7}$.

Sea cual fuere la opción que adopte el demandado la prueba de las obligaciones no se altera ${ }^{8}$, en tanto que en atención a lo prescrito en el art. 1698 CC. y aunque sea una obviedad ${ }^{9}$, merece la pena remarcarlo en este momento, por lo que más adelante se dirá. Por otra parte, se ha instalado en nuestra cultura que la actitud pasiva determina que toda la actividad probatoria recae en el demandante quien deberá demostrar todos sus dichos ${ }^{10}$. A pesar

${ }^{3}$ Por ejemplo, Casarino Viterbo, Mario, Manual de Derecho procesal. Derecho procesal civil. El proceso en general o reglas comunes a todo procedimiento (Santiago, Editorial Jurídica de Chile, 2009), III, p. 66, señala tres posibles opciones cuales son aceptar la demanda, no decir nada, o bien, defenderse

${ }^{4}$ Cortez Matcovich, Gonzalo, Segunda Parte. La fase de discusión, en Bordalí Salamanca, Andrés - Cortez Matcovich, Gonzalo - Palomo Vélez, Diego, Proceso civil. El juicio ordinario de mayor cuantía (Santiago, Abeledo Perrot - Thompson Reuters, 2013), p. 132.

${ }^{5}$ Couture, Eduardo, Fundamentos de Derecho procesal civil (Buenos Aires, Depalma, 1958), p. 197.

${ }^{6}$ Resulta interesante para este estudio señalar que el allanamiento ha sido correctamente tratado por la Corte Suprema. Baste como ejemplo la sentencia de la Primera Sala de la Corte 6697/2011 de 18 de agosto de 2011: "Si bien el allanamiento determina el contenido de la sentencia en orden a que, desaparecida la controversia, debe ella aceptar la pretensión de la parte demandante, no puede soslayarse que constituye un acto procesal de disposición, que, en lo sustancial se rige por lo dispuesto en el artículo 12 del Código Civil, concerniendo al solo interés individual de quien lo consuma; razón de quien lo consuma; razón por la que no puede afectar derechos de terceros que pudieran eventualmente aparecer comprometidos en el mismo juicio".

${ }^{7}$ Anabalón Sanderson, Carlos, Tratado práctico de derecho procesal civil (Santiago, Librotécnia, 1966), II.

${ }^{8}$ Prütting, Hans, Carga de la prueba y estándar probatorio: La influencia de Rosenbergy Karl Hainz Schwab para el desarrollo del moderno derecho probatorio, en Ius et Praxis, 16 (2010) 1, p. 457.

${ }^{9}$ Muy interesante resulta el reciente estudio a propósito de lo que prescribía el Proyecto: PAlomo Vélez, Diego, Las cargas probatorias dinámicas: ¿Es indispensable darse toda esa vuelta?, en Ius et Praxis, 19 (2013) 2, pp. 447-464.

${ }^{10}$ Figueroa YÁvar, Juan Agustín - Morgado San Martín, Erika, Jurisdicción, 
de ser cierto, no lo es menos que al demandante siempre le corresponderá esta carga en tanto debe generar la convicción en el juzgador para que acoja sus pretensiones ${ }^{11}$.

Habitualmente, nos concentramos, en este tema, para explicar que el demandado va a ser declarado rebelde o contumaz ${ }^{12}$. La no personación en la forma requerida por la ley ante el llamamiento que supone el emplazamiento determina la ausencia del demandado en el proceso siempre que sea declarada judicialmente ${ }^{13}$.

Una vez declarada judicialmente la rebeldía "se proveerá lo que convenga" ${ }^{14}$ para la prosecución del juicio. De este modo, en estricto rigor, lo que el demandado va a perder es el derecho a participar oportunamente de las actuaciones procesales, precluyendo, así, su oportunidad para defenderse ${ }^{15}$.

En todo caso, el aspecto de mayor trascendencia en este tópico dice relación con la consecuencia que le atribuimos a la rebeldía en la contestación de la demanda ${ }^{16}$. Es decir, si es que debemos entender que el demandado, atendido que el que calla otorga, se allana a todas las peticiones o, si bien

competencia y disposiciones comunes a todo procedimiento (Santiago, LegalPublishing Thompson Reuters, 2013), p. 26: "Nuestro legislador ha calificado, implícitamente, al silencio como defensa negativa tácita, y lo ha hecho equivalente con la circunstancia de controvertir los hechos en que se funda la pretensión, de esta manera es necesario recibir la causa prueba y el demandante quedará cargado con el onus probandi"

${ }^{11}$ Muy interesante resulta la respuesta a la pregunta: ¿para qué se prueba? Desarrollada por Devis Echandía, Bernardo, Compendio de pruebas judiciales (Bogotá, Temis, 1969), pp. 84-88). El autor recoge tres doctrinas: La prueba como medio de establecimiento de la verdad (Bentham, Ricci, Bonier); la prueba como convencimiento subjetivo del juez (Lessona, Furno, Chiovenda, Florian, Carrara, Rocco, Amaral Santos, Carnelutti) y la prueba como fijación de hechos en el proceso.

${ }^{12}$ En este sentido, véase: Carrasco Poblete, Jaime, La rebeldía en los procesos civil y laboral (Santiago, Abeledo Perrot - LegalPublishing, 2010).

${ }^{13}$ Rodríguez Garcés, Sergio, Derecho procesal funcional (Santiago, Vitacura, 1993), p. 177: "mantener un silencio, en una actitud pasiva, de inactividad frente al emplazamiento que ha sido objeto. Dejar pasar el término de emplazamiento sin hacer nada".

${ }^{14}$ Artículo 78 CPC.

${ }^{15}$ Como bien señala Correa Selame, Jorge, Curso de Derecho procesal (Santiago, Ediciones Jurídicas de Santiago, 2006), III, p. 69, el emplazamiento no genera una obligación en sí misma, sino más bien una carga procesal. En el mismo sentido, se pronunció Goldschmidt, James, Teoría general del proceso (Madrid, Labor, 1936) p. 89: "La rebeldía del demandado no es más que el descuidarse de una carga".

${ }^{16}$ En ningún caso, la contumacia produce la paralización del proceso, o bien, la vulneración a los principios de bilateralidad, contradicción o igualdad de armas. En este sentido, véase: Almagro Nosete, José, Derecho Procesal (Valencia, Tirant lo Blanch, 1992), p. 384. 
sucede alguna otra cosa y, en el fondo, ese principio no se aplica en nuestro ordenamiento jurídico.

\section{EL QUE CALLA NO OTORGA}

La solución comúnmente aceptada por la doctrina ${ }^{17}$ y por la jurispruden$\mathrm{cia}^{18}$ es que el demandado que adopta una posición contumaz no acepta las peticiones del actor $y$, además, no tiene por qué defenderse ${ }^{19}$. De este modo, simplemente, lo que estaría es perdiendo su oportunidad para hacerlo y su reincorporación al proceso determinará que deba aceptar todo lo que se obró mientras él no quiso participar del mismo ${ }^{20}$.

Se ha sostenido, entonces, que el que calla no otorga ${ }^{21}$. Sino más bien, que el que calla no dice nada ${ }^{22}$. El actor, entonces, mantiene su carga probatoria intacta y deberá hacerse cargo -demostrar- de los dichos que aseveró en su escrito de demanda ${ }^{23}$. Por su parte, el demandado perderá su posibilidad

${ }^{17}$ Anabalón Sanderson, Carlos, Tratado práctico del derecho procesal civil chileno (Santiago, Arancibia Hermanos Editores, 1963), III, p. 175: “La incontestación de la demanda no supone de parte del demandado la admisión de la misma, o sea, la aceptación de los hechos o fundamentos de derecho en que descansa, de suerte que siempre corresponderá al actor el onus probandi”.

${ }^{18}$ Por todas, la sentencia de la Sala Primera de la Corte Suprema, de 14 de marzo de 2011, rol No No 5817-11: "al no contestar la demanda el demandado se produjo el efecto de la contestación ficta, lo que significa, en términos concretos, que dich a parte ha negado la obligación".

${ }^{19}$ Ortells Ramos, Manuel, Derecho procesal civil, (Cizur Menor, Thompson Aranzadi, 2007), p. 310: "el emplazamiento o la citación no generan para el demandado ninguna obligación ni deber, sino una carga procesal”.

${ }^{20}$ Algo parecido podemos ver en la Partida VIII: "Aquel que calla, non se entiende que siempre otorga lo quel dizen, maguer non responda; mas esto es verdad, que non niega lo que oye".

${ }^{21}$ Podemos encontrar algunas manifestaciones específicas en Derecho Romano que indican lo contrario, sin embargo, no se podría afirmar una regla genérica y rotunda "qui tacet, consintere videtur", sino que de la influencia producida por estos casos y el desarrollo en el derecho canónico, encontramos el asidero que da sustento a esta norma. En este sentido, BetTi, Emilio, Declarazione voluntaria nella dogmatica bizantina, en Studi in memoria di E. Albertario (Milano, Giuffrè, 1953), II, p. 420.

${ }^{22}$ Benavente, Darío, Derecho procesal. Juicio ordinario. Recursos procesales (Santiago, Editorial Jurídica de Chile, 1991), p. 20. El profesor Benavente explica con diáfana claridad que "quien calla no dice nada" y por lo tanto "no otorga". Además, señala enfáticamente que no se debe presumir que todo lo dicho por el actor es efectivo y, por este motivo, le corresponderá acreditar los hechos que afirma.

${ }^{23}$ Jorguera Lorca, René, Sintesis de derecho procesal civil (Santiago, Ediciones Jurídicas La Ley, 1995), p. 18: "Si el demandado no dice nada frente a la demanda, no 
inicial de defensa, pero si no otorga, en el fondo la consecuencia de su acto será la negación genérica de la pretensión ${ }^{24}$.

Así, curiosamente, pudiéramos concluir que de la actitud del que no se defiende, del que calla, se colige que niega la pretensión en todos sus puntos $\mathrm{y}$, de este modo, convertirá a todos los hechos en controvertidos ${ }^{25}$. De esta forma, se genera un beneficio de defensa ya que se determina que todos los hechos puedan (cuando el juez lo considere oportuno) ser objeto de prueba, siempre que cumplan con los otros dos requisitos que deberá calificar el tribunal (pertinencia y sustancialidad). Al punto, que esta presunción acarrea una negación que, probablemente, resultaría hasta más compleja conseguirla contestando la demanda. Es decir, pudiera ser, en función de la complejidad de la demanda, que llegue a generar mayor dificultad técnica jurídica realizar una negación de cada uno de los hechos afirmados por el actor en su escrito, que no esta consecuencia por la que, inmediatamente, los niega todos ${ }^{26}$.

Mediante esta solución ${ }^{27}$, finalmente, se consigue mantener la igualdad de armas y que sean los hechos probados los que conduzcan al juez a la solución más justa y más cercana a la verdad ${ }^{28}$.

Ahora bien, esta previsión no sanciona ${ }^{29}$ al demandado que tiene una actitud estratégicamente contumaz con el objeto de generar dilaciones y ni siquiera teniendo en cuenta la obligación, al menos, ética de colaborar con

por ello se va a presumir que todo lo dicho en ella es efectivo. El actor deberá acreditar, pues, los hechos que sirven de fundamento a su demanda".

${ }^{24}$ Figueroa Yávar, Juan Agustín - Morgado San Martín, Erika, cit. (n. 10), p. 26.

${ }^{25}$ Resulta muy interesante analizar qué sucede en el caso de la ficta confessio descrita por Orellana Torres, Fernando - Pérez Ragone, Álvaro, Radiografía de la rebeldía en el proceso civil: Tópicos hacia una adecuada regulación de la nueva justicia civil, en Ius et Praxis, 13 (2007) 2, p. 20.

${ }^{26}$ Ibíd., p. 31.

${ }^{27}$ Principalmente, la institución de la rebeldía ha sido concebida como un beneficio para la parte que reclama legítimamente un derecho y con la inactividad de la contraria pudiera verse afectada si se hubiera previsto que el proceso quedara en suspensión hasta la personación de la parte. En este sentido, González, Atilio Carlos, Silencio y rebeldia en el proceso civil (Buenos Aires, Astrea, 1995), p. 95; Ortells Ramos, Manuel, cit. (n. 19) p. 321.

${ }^{28}$ Solución que provocaría disconformidad en parte de la doctrina. Alvarado Velloso, Adolfo, Introducción al estudio del derecho procesal (Buenos Aires, Editorial Rubinzal, 2000), I, p. 180, entiende que debe interpretarse que el demandado acepta tácitamente los hechos afirmados y, en consecuencia, éste queda relevado de confirmarlos.

${ }^{29}$ Carretta Muñoz, Francesco, Deberes procesales de las partes en el proceso civil chileno: referencia a la buena fe procesal y al deber de coherencia, en Revista de Derecho de la Universidad Austral de Chile, 21 (2008) 1, p. 107. 
la Administración de justicia, por lo que quizá consigue que la decisión sea judicialmente justa a costa de prestar una tutela excesivamente garantista ante la inacción del deudor ${ }^{30}$.

Pudiera ser, entonces, que inspirado en la máxima de cooperación en el proceso civil ${ }^{31}$, el derecho brasileño optara por considerar verdaderas las alegaciones de hecho afirmadas por el demandante si no hay contestación ${ }^{32}$.

Resulta importante recordar que el Código de Procedimiento Civil regula en el título $7^{\circ}$ del libro II la contestación y aquellos otros trámites que nos conducen al periodo de prueba. Además de la propia contestación, contamos hoy con la posibilidad de interponer las excepciones de prescripción, cosa juzgada, transacción y pago en todo momento; tenemos la posibilidad de que se dé la réplica y la dúplica y, también, las partes pueden solicitar sin mayor trámite que se dicte sentencia ${ }^{33}$.

\section{El QUe CAlla PUEDE OTORgaR}

Actualmente, sabemos que no basta con contestar la demanda para que el tribunal decida abrir el periodo probatorio y genere un espacio de mayor grado de defensa del demandado, al permitirle rendir pruebas que desvirtúen los dichos de la demandante. Al contrario, el artículo 313 CPC. impone diáfanamente al demandado la carga de contradecir los hechos sobre los que versa el juicio o, de lo contrario, el tribunal citará a las partes a oír sentencia, una vez que se haya evacuado el traslado para la réplica, en su caso ${ }^{34}$. De hecho, una lectura correcta del art. 318 CPC. solamente nos

${ }^{30}$ En este sentido, Carrasco Poblete, cit. (n. 12) p. 45: “Una sentencia del año 1929, ilustra claramente que “[...] la contestación tácita es negativa y que, por tanto, queda trabada la litis con la demanda que afirma la ficción legal de darla por contestada negativamente, de otro modo no podría haber la controversia que emana de los autos y que debe ser estimada por el Tribunal". De lo expuesto, se deduce que, en la especie la demanda solo será acogida si el actor justifica sus pretensiones tanto en el hecho como en el derecho. Resulta interesante lo anterior puesto que si el actor no logra probar su pretensión el juez debe rechazar la demanda y por lo tanto el rebelde que permaneció en tal actitud durante toda la instancia gane el pleito".

${ }^{31}$ Souza, Artur, Contraditório e revelia. Perspectiva crítica dos efeitos da revelia em face da naturaleza diaética do proceso, en Revista dos Tribunais (2003) 1, p. 230.

${ }^{32}$ Marinoni, Luiz, Novas linhas do processo civil (Sao Paulo, Malheiros, 2000), p. 248.

${ }^{33}$ Rodríguez PAPIC, Ignacio, Procedimiento civil. Juicio ordinario de mayor cuantía (Santiago, Editorial Jurídica de Chile, 2012).

${ }^{34}$ En este sentido, la sentencia de la Corte de Apelaciones de Antofagasta, de 27 de mayo de 2008, rol No No 874-2007: "Que el allanamiento del demandado, de acuerdo lo dispone el artículo 323 del Código de Procedimiento Civil, sólo determina la actitud del tribunal en cuanto a citar a las partes a oir sentencia por no existir hechos sustanciales, 
puede llevar a concluir que la prueba versará exclusivamente sobre hechos substanciales, pertinentes y controvertidos ${ }^{35}$. Por lo tanto, los hechos que no cumplan estas características podrán ser admitidos como ciertos por el órgano jurisdiccional ${ }^{36}$.

Así pues, el Código de Procedimiento Civil, en cierto modo, está imponiendo la carga, deber u obligación de defenderse bajo la consecuencia de perder la oportunidad de proponer y rendir prueba a su favor ${ }^{37}$. Más aún, al no controvertir los hechos substanciales y pertinentes del demandante el juez los podría tener por ciertos y liberaría de la carga de probarlos al faltar uno de los requisitos esenciales para que operen las normas de distribución de la carga de la prueba ${ }^{38}$.

En otras palabras, podríamos llegar a afirmar, que al contrario de lo que habitualmente se postula: quien calla sí otorga ${ }^{39}$. Quizá podríamos ampliar el alcance de esta conclusión indicando que existe una necesidad imperiosa de controvertir ${ }^{40}$ aquellos hechos que el tribunal pueda calificar de pertinentes y substanciales, ya que de lo contrario los dará por admitidos, en contra de

pertinentes y controvertidos, omitiendo la recepción de la causa a prueba, pero no influye en la calificación jurídica de la situación ni en sus consecuencias legales, no pudiendo el allanamiento revestir el carácter de prueba fundamental para dar por acreditados los hechos en materia de la demanda como lo asevera el recurrente, ya que siempre tendrá el tribunal la potestad de decir el derecho, más aún en un caso como éste en que la demandante se allana a su propia demanda, en tanto existe un demandado que ha controvertido los hechos".

${ }^{35}$ Sentencia de la Corte Suprema, de 14 de enero de 2011, rol ํ № 3780-2009.

${ }^{36}$ Efectivamente, una de las críticas a la búsqueda de la verdad como función de la prueba es realizada por PALOMO VÉLEZ, Diego, La audiencia previa y el modelo procesal civil oral: consideraciones en torno a una pieza procesal clave, en DE LA Oliva, Andrés Palomo Vélez, Diego, Proceso civil. Hacia una nueva justicia civil (Santiago, Editorial Jurídica de Chile, 2007), p. 236: "Valga recordar respecto de este punto lo señalado en cuanto a que los hechos afirmados por ambas partes deben ser tenidos como ciertos por el juzgador, lo que impide suscribir la corriente que postula la búsqueda y descubrimiento de la "verdad".

${ }^{37}$ Específicamente, adherimos la opinión de Ortells Ramos, Manuel, cit. (n. 19), p. 310, quien habla de carga. Señala, a su vez, Couture, Eduardo, Estudios de derecho procesal civil (Buenos Aires, Ediar), I, p. 46: "lo que se le otorga al demandado es la eventualidad de la defensa".

${ }^{38}$ Casarino Viterbo, Mario, cit. (n. 3), p. 66: "libera al juez de la obligación de recibir la causa a prueba, limitándose simplemente a citar a las partes para oír sentencia, pero siempre que se hayan evacuado los trámites de réplica y dúplica”.

${ }^{39}$ En contra de esta afirmación encontraríamos a RAmos Méndez, Derecho procesal civil (Barcelona, Bosch, 1985), I, p.486, quien es categórico al señalar que no existe el allanamiento tácito y, por lo tanto, éste debe ser expreso al corresponderse con una declaración de voluntad que determina un acto de trascendencia en el contenido de la sentencia.

${ }^{40}$ Sentencia de la Corte Suprema, de 30 de mayo de 2011, rol N № 7787-09. 
quien no habló para discutirlos. Por lo tanto, pese a que nadie está obligado a defenderse, ello sí acarrea una importante consecuencia para la parte que tiene esta actitud pasiva, ya que, no solo perderá su oportunidad de proponer prueba, sino que estará admitiendo los hechos afirmados por el demandante y lo estará liberando de la carga de la prueba ${ }^{41}$.

La solución, por lo visto hasta el momento, nos llevaría a señalar que quien calla otorga, por una parte, y que quien calla no otorga, por la otra ${ }^{42}$.

Esta disyuntiva tiene un origen histórico. Se produce desde que el papa Bonifacio VIII incorporó un Liber sextus a las Decretales. Ahí dedicó un acápite a las reglas en juicio (De regulis iuris) ${ }^{43}$. En la regla $43^{\text {a }}$ se dice "qui tacet, consintire videtur" y en la 44 "is, qui tacet, non fatetur, sed nec utique negare videtur" ${ }^{\text {"14 }}$. En ese momento se establecieron dos normas que, en cierto modo, sobreviven hasta nuestros días, puesto que por una parte el que tolera o no controvierte pareciera ofrecer una declaración positiva de consentimiento, y por otra, el que es taciturnitas (el que calla y de esa actitud se puede sobrentender una manifestación de voluntad) está prestando su consentimiento, pero solamente en los casos que la ley o el juez, así lo consideren ${ }^{45}$. Estas reglas del Liber Sextus permearon a la doctrina y jurisprudencia y, del mismo modo, al Derecho común, generando hoy esta doble situación que no solo existe en nuestro entorno puramente cultural, sino en la redacción de nuestros textos jurídicos ${ }^{46}$.

${ }^{41}$ Montero Aroca, Juan, Derecho jurisdiccional, II: Proceso civil. (Valencia, Tirant lo Blanch, 2013), p. 216: "Sin alegar hechos nuevos y admitiendo los alegados por el actor el demandado deja reducida la cuestión a una controversia jurídica".

${ }^{42}$ Tras señalar que el periodo de prueba es eventual, PALOmo VéLEZ, Diego, cit. (n. 36), p. 218) realiza una reflexión muy interesante al señalar: “'Se tendrá que recibir la causa a prueba en los casos antes señalados? En los dos primeros casos, esto es, cuando el demandado ha aceptado llanamente las peticiones del actor, o si en sus escritos no contradice en materia sustancial y pertinente los hechos sobre que versa el juicio, la respuesta es negativa a menos que quisiera desplegarse de todos modos una actividad probatoria sin ningún objeto, con el consiguiente malgasto de recursos y tiempo, y la encontramos, en nuestra legislación procesal, en el art. 313.1 que prescribe que en esas hipótesis no procede la recepción de la causa a prueba, sino que se cite a las partes a oír sentencia".

${ }^{43}$ Schulz, Fritz, Principles of Roman Law (Oxford, Oxford University Press, 1956), p. 212.

${ }^{44}$ Liber Sextus Decretaliun, Corpus Iuris Canonici (Leipzig, Inst. Friedberg, 1881), p. 1.123 .

${ }^{45}$ Magni, Cesare, Il silenzio nel diritto canonico, en Rivista di Diritto Privado (1934) 1, p. 53.

${ }^{46}$ Por poner solamente un ejemplo, la Ley de Enjuiciamiento Civil española 1/200 también cuenta con este doble efecto del silencio en función de la comparecencia o no. Así, dispone en su artículo 405,2: "El tribunal podrá considerar el silencio o las respuestas 
Consideramos que en el tratamiento de este tema no se ha reparado suficientemente, o no se ha dejado tan claro como sería deseable que el demandado que no se defiende suficientemente sí pudiera estar otorgando con su actitud. Efectivamente, el artículo 313 CPC. ha equiparado las acciones de allanarse y no contradecir en materia sustancial y pertinente los hechos. De ahí, entonces, que nos encontremos con dos consecuencias diferentes ante el silencio. Se castiga más, podríamos decir, a quien comparece y no confronta los hechos, que a quien no se persona ${ }^{47}$.

Resulta interesante destacar que el Código de Procedimiento Civil, entonces, sí consagra al silencio, en algunos casos como generador de aceptación tácita de hechos. Aunque se debe reconocer que incluso en ese supuesto, no es una conclusión automática en tanto que depende de que exista falta de capacidad para disponer, o bien se encuentre comprometido el interés públi$\mathrm{co}^{48}$. Pero, por lo señalado hasta el momento, inequívocamente, el precepto equipara aceptación llana con no contradicción suficiente y sanciona con el mandato al tribunal de citar a oír sentencia definitiva, una vez evacuado el trámite del traslado de la réplica ${ }^{49}$.

Sin embargo, el artículo 318 CPC. entrega plena potestad al juez para recibir la causa a prueba si es que estima que hay o puede haber controversia sobre los hechos ${ }^{50}$. Esta previsión parece generar una suerte de incompatibilidad entre ambos mandatos ${ }^{51}$. Así, en una secuencia lógica podríamos decir que a tenor de lo dispuesto en el artículo 313 CPC. si el demandado no contradice los hechos alegados por el demandante, lo libera de la carga de la prueba porque el tribunal, igual que en el supuesto de que las partes lo pidan, debe llamar a oír sentencia.

Por otra parte, el artículo 318 CPC. parece morigerar ese mandato. El

evasivas del demandado como admisión tácita de los hechos que le sean perjudiciales" y, por otra parte, el artículo 496.2 al tratar la rebeldía, señala: "La declaración de rebeldía no será considerada como allanamiento ni como admisión de los hechos de la demanda, salvo los casos en que la ley expresamente disponga lo contrario".

${ }^{47}$ Incluso, interesantemente, se ha señalado que desde el punto de vista estratégico podría resultar una opción mejor no comparecer, que hacerlo para no decir verdad. Así, Figueroa Yávar, J. A. - Morgado San Martín, E., cit. (n. 10), p. 32: "Esto tiene también un contenido estratégico, ya que es mejor no comparecer a comparecer negando, porque así no se queda como mentiroso y tiene los mismos efectos".

${ }^{48}$ JorQuera LorCa, René, cit. (n. 23), p. 19.

${ }^{49}$ Ibíd., p. 20.

${ }^{50}$ Sentencia de la Corte Suprema, de 28 de julio de 2010, rol N No $^{\circ} 683-09$.

${ }^{51}$ Afortunadamente, en la práctica no se produce esta incompatibilidad puesto que la parte se ve obligada a presentar un escrito cuyo objetivo es solicitar que se reciba la causa a prueba evitando, de este modo, que se convierta en algo parecido a una potestad del juez; véase: Palomo VÉlez, Diego, cit. (n. 36), pp. 218-219. 
Código deja en claro que es una potestad del juez recibir la causa a prueba. A su vez, esta circunstancia se dará siempre que existan hechos substanciales controvertidos surgidos de los escritos anteriores al auto de prueba. Así las cosas, si los hechos no fueron controvertidos, no podrían ser incluidos como punto de prueba y, por lo tanto, se corroboraría la aceptación tácita de hechos ${ }^{52}$.

A mayor abundamiento, como medio de control, recordamos que el artículo 319 CPC. permite la interposición de recurso de reposición, con apelación subsidiaria, cuyo objetivo es que se añadan o eliminen hechos controvertidos $^{53}$. Perfectamente, el fundamento de este recurso podría ser la ausencia de controversia en los hechos.

Entonces, ¿el que calla otorga? La respuesta en este momento en virtud de lo constatado debiera ser: hay que distinguir. En esta distinción deberíamos señalar que lo determinante es el momento del ejercicio del silencio. Si el silencio fue absoluto y no se realizó ninguna actuación tendiente a desvirtuar la pretensión del actor, es decir, ni tan siquiera hubo personación tras el emplazamiento, el que calla no otorga. Ahora bien, aquel que contestó la demanda o realizó actuaciones tendientes a defenderse, en plazo y forma, podrá generar con su silencio sobre algunos o todos los puntos aceptación tácita de todo lo que no controvierta.

\section{Actitudes frente a la demanda en el "Proyecto de Código Procesal Civil”}

El Proyecto de Código Procesal Civil regula en el libro II, título $1^{\circ}$, capítulo $3^{\circ}$, las actitudes del demandado frente a la demanda. El Proyecto recoge las clásicas actitudes que básicamente, podríamos categorizar en dos: una actitud activa y una actitud pasiva.

En primer lugar, pudiera adoptar una conducta activa y ella se deberá materializar en diferentes opciones: allanarse total o parcialmente, plantear excepciones previas, también contestar la demanda e incluso reconvenir, a tenor de lo dispuesto por el propio artículo 265 PCPC. que contempla estas

${ }^{52}$ En este mismo sentido, explica Carocca Pérez, Manual de derecho procesal, II: Los procesos declarativos (Santiago, LexisNexis, 2003), p. 186, que no tendrá lugar la prueba: "Si el demandado no contradice de manera sustancial y pertinente los hechos afirmados por el demandante en sus escritos de alegaciones, también deberá citar a las partes para oír sentencia, omitiendo la fase de prueba (art. 313 inc. $1^{\circ} \mathrm{CPC}$ ). Aunque en este evento, ya no será una obligación del tribunal, sino una decisión suya (art. 318 inc $\left.1^{\circ} \mathrm{CPC}\right)$, que incluso podrá ser recurrida por las partes".

${ }^{53}$ Orellana Torres, Fernando, Manual de derecho procesal. Procedimientos civiles ordinarios y especiales (Santiago, Librotecnia, 2006), p. 236. 
posibilidades. A su vez, el demandado que opte por tomar una postura pasiva determinará que el tribunal, según prescribe el artículo 264 PCPC., deberá tener por evacuado el trámite de contestación y continuará el proceso, por el solo ministerio de la ley.

Importa, a los efectos de este estudio, destacar que la experiencia acumulada durante estos años ha hecho que el legislador contemple algunas sanciones a esa actitud, con el objetivo de agilizar el proceso ${ }^{54}$. Así pues, se establece que no será necesario continuar notificando al demandado de cada una de las resoluciones que se dicten, produciendo sus efectos desde el momento en que se dicten ${ }^{55}$. Solamente, se contemplan dos excepciones: a saber, la resolución que cita a audiencia preliminar y la sentencia definitiva de primer grado que deberán notificarse, en todo caso, por cédula ${ }^{56}$.

De este modo, podemos decir que se producirá un efecto general de la declaración de rebeldía desde el momento en que el demandado no haga uso de su derecho a la contestación de la demanda ${ }^{57}$. Efecto general, eso sí, atenuado por las dos excepciones comentadas.

Por otra parte, la sanción al demandado rebelde no es tan grave para coartar todos sus derechos y se le permite reincorporar al proceso en cualquier momento, con el perjuicio de respeto a todo lo obrado ${ }^{58}$.

Pudieran parecer pocos los cambios, sino fuera porque además el Proyecto

${ }^{54}$ Efectivamente, Orellana Torres y Pérez Ragone señalaron cómo el Foro para la Reforma de la Justicia Civil en Chile se hizo eco de este asunto: "Por fin, es indispensable regular el silencio o rebeldía procesal, en cuanto a si implica una admisión o por el contrario una negación de los presupuestos fácticos de la pretensión. Así como en los procesos modernos se sanciona la incomparecencia del actor a la audiencia preliminar o preparatoria de un juicio oral con la pérdida de su derecho material, se sanciona de contrario al demandado con una presunción de aceptación provisional de los hechos afirmados por el actor, disuasivos ambos suficientemente poderosos de un abuso del sistema jurisdiccional. Lo anterior requiere una posición normativa hasta la fecha entregada a confusas opiniones doctrinarias y jurisprudenciales [...]" (Radiografía de la rebeldia en el proceso civil: Tópicos hacia una adecuada regulación de la nueva justicia civil, en Ius et Praxis, 13 (2007) 2, pp. 42-43).

${ }^{55}$ Recordemos que con la regulación vigente distinguimos los efectos de la rebeldía en primera y segunda instancia. En segunda instancia produce un efecto general como el descrito. Sin embargo, actualmente en primera instancia "este efecto solo tiene incidencia para el acto concreto, ya que sólo precluye el derecho para realizar el acto que no se verificó en el plazo no fatal, pero las resoluciones que se dicten con posterioridad en la causa deben seguir siendo notificadas al litigante rebelde" (SAlas Astrain, Jaime Iván, Nuevo derecho procesal (Santiago, El Jurista Ediciones Jurídicas, 2010), p. 461).

${ }^{56}$ Artículo 264 PCPC.

${ }^{57}$ Sucederá lo que actualmente está contemplado para la segunda instancia del modo señalado por Cortez Matcovich, Gonzalo, cit. (n. 5), p. 128.

${ }^{58}$ Artículo 264 PCPC. en su inciso final establece: "El demandado rebelde podrá 
de Código Procesal Civil expresa explícitamente el efecto principal que genera la rebeldía respecto de los hechos afirmados por el actor. Así, "La rebeldía del demandado importará una negación de los hechos afirmados por el actor en su demanda, pero no podrá rendir prueba en juicio, salvo en la forma y condiciones previstas en el artículo $276^{\prime 59}$.

Observamos, entonces, varias novedades. En primer lugar, el Proyecto se encarga de establecer positivamente que el demandado realiza una negación genérica de los hechos, acogiendo lo señalado por la doctrina ${ }^{60}$. Así, el demandado, niega todo lo dicho por el actor.

Resulta novedoso y quizá extraño. Especialmente, después de lo acontecido en materia de proceso laboral. Efectivamente, el Código del Trabajo contempla una prescripción que de forma mucho más clara explicita que "quien calla otorga", ya que el demandado que no contesta la demanda o que no niega algunos de los hechos contenidos en la demanda quedará en situación de que el juez, potestativamente, pueda estimar aquellos como tácitamente admitidos ${ }^{61}$.

Pero, además, en el Proyecto se añade una nueva consecuencia negativa a su inacción: se le prohíbe rendir prueba en juicio ${ }^{62}$.

El legislador ha querido potenciar la colaboración e implicación de las partes $^{63}$, al punto que se suma una grave consecuencia como la de no poder rendir prueba en la audiencia de juicio. Sin duda, existe un incentivo impor-

comparecer en cualquier estado del proceso, pero respetando lo que se hubiere actuado con antelación".

${ }^{59}$ Artículo 264 PCPC.

${ }^{60}$ Se realiza una correcta actualización de la legislación procesal que ya había sido señalada por la doctrina. Por todos, véase lo señalado por Rodríguez PAPIC, Ignacio, cit. (n. 33), p. 40: Precluido el derecho del demandado de contestar la demanda se produce lo que en doctrina se llama "contestación ficta de la demanda", pero ello no significa que el demandado acepte lo dicho en la demanda, porque en derecho quien calla no otorga, sino que sencillamente no dice nada; por consiguiente, el actor deberá probar los hechos en los que se basa su acción (pretensión)".

${ }^{61}$ Esta previsión se introdujo en nuestro ordenamiento jurídico desde el "Mensaje" presidencial 4-350, de 22 de septiembre de 2003 que encabezaba el proyecto de ley que sustituía el procedimiento laboral. En primer lugar, estaba consignada en el artículo 455, hasta que el primer informe de la Comisión de Trabajo de 7 de septiembre de 2004 la terminó estableciendo en el artículo 453 con un tenor muy parecido al actual.

${ }^{62}$ Samanes ARA, Carmen, La tutela del rebelde en el proceso civil (Barcelona, Bosch, 1993), p. 101: "por el principio de preclusión la parte que deja de realizar una actividad procesal en el momento o plazo que la ley prevé para ello, pierde la oportunidad de hacerlo más tarde, es decir, queda impedida o precluida de hacerlo".

${ }^{63}$ En este sentido, véase Ruay Sáez, Francisco Alberto, Análisis critico sobre la inclusión del principio de buena fe procesal en el "Proyecto de Código Procesal Civil" chileno, en Revista de Derecho y Ciencia Politica, 4 (2013) 3. 
tantísimo para estimular la participación activa del demandado en el periodo de discusión. Además, se genera un contrapeso necesario ya que debemos recordar que el demandante está obligado a "mostrar todas sus cartas" junto con su escrito de demanda ${ }^{64}$.

En este diseño, la audiencia preliminar ${ }^{65}$ tiene todo el sentido de ser un momento procesal destinado a concretar al detalle el objeto de debate y evitar aquellas fórmulas utilizadas por los litigantes que bajo el anuncio de "cómo en la oportunidad procesal se acreditará" postergaban sus estrategias y, finalmente, las partes nunca tenían claro cuál era realmente el objeto de debate y el material probatorio del que se disponía.

Además, se concede otra oportunidad para contribuir a centrar la discusión y proponer prueba visto lo establecido por el artículo 276 PCPC. Así, pese a que las partes no pueden alterar lo declarado en la demanda y contestación $^{66}$, en la audiencia preliminar sí pueden realizar observaciones a lo expuesto por la parte contraria con el objetivo de aclarar o modificar las pretensiones. Además, si tras el momento procesal de contestación ocurrieran hechos nuevos o hubiera llegado noticia sobre un hecho relevante, estos sí podrían alegarse por estricto o, a más tardar, en la audiencia preliminar y, por lo tanto, calificada su conducencia se podría solicitar rendir prueba sobre los mismos ${ }^{67}$. De modo, que todavía queda una puerta entre abierta a

${ }^{64}$ Efectivamente, el artículo 254 PCPC. viene a restablecer una obligación que se había derogado mediante el art. 1 No 44 de la Ley $\mathrm{N}^{\circ} 18.705$ en el año 1988. Hasta aquel entonces, debían acompañarse tanto los documentos en que se fundaba su derecho, como los documentos que solo justificaban la interposición de la demanda (Casarino Viterbo, Mario, cit. (n. 3), p.23). De este modo, no haría falta buscar antecedentes en la institución del discovery cuyo origen anglosajón lo aleja de nuestro entorno jurídico-cultural.

${ }^{65}$ Para un correcto entendimiento de esta figura, Palomo VéLez, Diego, cit. (n. 36), p. 377.

${ }^{66}$ Magro Servet, Vicente, Los hechos nuevos o de nueva noticia y las alegaciones complementarias en la LEC, en La Ley 7139 (2009) 1, p. 1307: "la prohibición de la mutatio libelli rige en general el procedimiento a partir del cierre o preclusión del periodo alegatorio (así en los juicios declarativos, los arts. 400, 412, 414, 426 y 443, en relación con el art. 222.2 LEC), tanto en lo que se refiere a los hechos como a la relación jurídica objeto de litigio, de manera que cualquier cambio o innovación de la cuestión controvertida, tal y como ha quedado definida, realizada extemporáneamente, conculca una garantía fundamental del proceso vinculadas al derecho constitucional de defensa (art. 24 CE)".

${ }^{67}$ Esta institución es conocida en derecho comparado. Por ejemplo, CorTÉs Domínguez, Valentín - Moreno Catena, Víctor, Derecho procesal civil. Parte general (Valencia, Tirant lo Blanch, 2010), p. 178: "aquellos hechos nuevos ocurridos con posterioridad a los escritos de demanda y contestación, y aquellos hechos de los que se 
la alegación de hechos y solicitud de prueba, mediante una interpretación amplia de este precepto ${ }^{68}$.

Pareciera, por lo tanto, que en armonía con el Código de Procedimiento Civil en esta reforma se mantiene el principio general de que el que calla no otorga. Sería una postura conservadora y si tenemos en cuenta las consecuencias jurídicas reguladas positivamente, diríamos que se ha avanzado en igualdad para el demandante y para la conducción de un proceso civil en el que las partes sean activas y participen, dentro de los órdenes de preclusión.

Sin embargo, esta afirmación debemos tomarla a beneficio de inventario una vez revisemos el contenido detallado del artículo 272 PCPC.

\section{La Contestación de la demanda en el "Proyecto de Código Procesal Civil”}

Entre las actitudes que puede adoptar del demandante se encuentra una de las más, sino la que más, paradigmáticas como es contestar. De este modo, se conformaría un objeto litigioso perfecto en el que en igualdad de oportunidades ${ }^{69}$, las partes disponen a cabalidad de su conflicto sometiéndolo a conocimiento de un órgano jurisdiccional que intervendrá para calificar el material probatorio y tras la rendición del mismo se podrá pronunciar informadamente sobre el fondo del asunto.

La contestación de la demanda deberá ser por escrito ${ }^{70} \mathrm{y}$, según las enunciaciones del artículo 271 PCPC. deberá contener los requisitos formales clásicos $^{71}$ : en primer lugar, la designación del tribunal ante el que se está tramitando el asunto; la individualización del demandado y su domicilio;

hubiese tenido noticia con posterioridad a los escritos de demanda y contestación y, lógicamente con anterior a la audiencia o a la vista".

${ }^{68} \mathrm{El}$ artículo 276 PCPC. consagra la inalterabilidad del contenido de la demanda, la contestación y la reconvención. Sin embargo, también consagra que se pueden realizar alegaciones complementarias, como las que teóricamente se pueden realizar mediante los escritos de réplica y dúplica antes de cerrar el periodo de discusión. Sin embargo, llama la atención positivamente que se permita alegar hechos que o bien sucedan después de la notificación de la demanda o después de la contestación o reconvención, siempre que hayan llegado a conocimiento de la parte, se trate de hechos relevantes y tengan la característica de no haber podido, ni debido, ser conocidos con anterioridad. En este caso, estos hechos se ponen en conocimiento del tribunal en forma escrita, o a más tardar, en la audiencia preliminar. Quedará, eso sí, a criterio del tribunal la discreción de aceptarlos o rechazarlos de plano cuando encuentre que no tengan suficiente relevancia, o que pudieron ser conocidos anteriormente.

${ }^{69}$ Artículo 4 PCPC.

${ }^{70}$ Artículo 270 PCPC.

${ }^{71}$ Cortez Matcovich, G., cit. (n. 5), p. 152, señala que los requisitos formales son: que se presente en forma escrita, antes del vencimiento del término de emplaza- 
el petitorio elevado al órgano jurisdiccional y las firmas del demandado y su abogado ${ }^{72}$.

Junto con estos requisitos el ordinal tercero señala que se debe consignar la exposición clara y precisa de los hechos que constituyen las defensas o excepciones que el demandado opone en su escrito. Y, a su vez, deben señalarse los medios de prueba de los que se pretende valer para demostrar aquellos hechos. Además, se debe indicar el derecho en que se fundan las peticiones.

De este modo, en poco difiere lo previsto en el Proyecto de Código Procesal Civil con lo prescrito en el 309 CPC. Sí se nota una mejoría en la técnica y actualización del uso del lenguaje y se incorpora la necesidad de firmar el escrito, de modo más acorde con la práctica y las demás normas del ordenamiento jurídico procesal.

Quizá, lo más significativo, en este extremo pueda resultar la reintroducción de una previsión que contemplaba el Código de Procedimiento Civil en su versión original de $1902^{73}$. Efectivamente, en concordancia con lo establecido para la demanda ${ }^{74}$, el demandado debe acompañar toda la prueba documental de la que pretenda valerse y si no dispusiera de alguno de los documentos

miento; que se individualice al tribunal y a las partes y se planteen las defensas de fondo de las que se quiera valer el demandado.

${ }^{72} \mathrm{~A}$ diferencia de lo que ocurre en la actualidad que las normas de comparecencia están recogidas en la Ley $\mathrm{N}^{\circ} 18.120$.

${ }^{73}$ Artículo 299 (CPC. 1902): "La contestación de la demanda deberá contener:/ 1. La designación del tribunal ante quien se presente;/ 2. El nombre, domicilio i profesión $u$ oficio del demandado;/3. Las excepciones que se oponen a la demanda i la exposición clara de los hechos i fundamentos de derecho en que se, apoyan; i/4. La enunciación precisa i clara, consignada en la conclusión, de las peticiones que se sometan al fallo del tribunal./ Son también aplicables a la contestación de la demanda $i$ al demandado las disposiciones del artículo 252". Por su parte, el artículo 252 en su redacción original, señalaba: "El actor deberá, presentar con su demanda los instrumentos en que la funde./ Si no se diere cumplimiento a esta disposición, exigiéndolo el demandado, los instrumentos que se presentaren después solo se tomarán en consideración si el demandado los hiciere también valer en apoyo de su defensa, o si se justifica o aparece de manifiesto que no pudieron ser presentados antes, o si se refieren a hechos nuevos alegados en el juicio con posterioridad a la demanda.l En estos casos, si la presentación se hiciere después de espirado el término probatorio o no hubiere habido lugar a este trámite, podrá el tribunal, a petición del demandado, abrir un término especial, con relación a los nuevos instrumentos acompañados; i se tramitará esta gestión en pieza separada, según las reglas establecidas para los incidentes, suspendiéndose el juicio principal solo en el momento de dictar sentencia definitiva, si el incidente no bubiere terminado".

${ }^{74} \mathrm{El}$ artículo 254 PCPC. señala expresamente: "El actor deberá acompañar con su demanda, en conformidad a la ley, toda la prueba documental de que se intente valer". 
podrá reseñarlos y solicitar al juez que disponga las medidas más oportunas para incorporarlos al proceso $^{75}$.

\section{DeMÁs TRÁMITES EN EL "Proyecto de Código Procesal Civil"}

El Proyecto de Código Procesal Civil no regula bajo el mismo título los trámites anteriores al periodo de prueba que el Código de Procedimiento Civil. Entre otros motivos, porque existe un trámite nuevo y anterior que es la audiencia preliminar y, por otra parte, porque refunde en el capítulo $3^{\circ}$ : "De las actitudes del demandado frente a la demanda", los actuales títulos $7^{\circ}$ y $8^{\circ}$ que regulan las temáticas atingentes a la contestación y la reconvención. Pero contempla una regulación con alto grado de similitud incardinada en las normas que regulan las actitudes del demandado ante la demanda.

De este modo, además de las actitudes ya nombradas, se regula la tramitación de las excepciones previas ${ }^{76}$; la obligatoriedad de acompañar toda la documental y ofrecer la demás prueba con la contestación ${ }^{77}$; la carga que surge para el demandante de controvertir los documentos del demandado ${ }^{78}$; se regula la demanda reconvencional ${ }^{79}$; se permiten alegaciones complementarias y la introducción de hechos nuevos desconocidos o de nueva noticia ${ }^{80}$; $\mathrm{y}$, finalmente, se consagra la obligación para el tribunal de citar a audiencia $\operatorname{preliminar}^{81}$.

En este caso, llama la atención la carga que impone el artículo 272 PCPC. Efectivamente, el citado artículo prescribe que en la contestación el demandado deberá controvertir los hechos y la prueba documental acompañada por el demandante (pronunciarse categórica y precisamente sobre la veracidad de los hechos alegados en la demanda y sobre la autenticidad, integridad y validez de los documentos que a ella se hubieren acompañado). Al ser una carga, como reza la norma, se prevé una consecuencia derivada de su incumplimiento.

El demandado que no cumple con esta obligación legal determinará la posibilidad de que el tribunal considere que admite los hechos que le resultan perjudiciales así como los documentos acompañados oportunamente ${ }^{82}$.

\footnotetext{
${ }^{75}$ Artículo 254 PCPC.

${ }^{76}$ Artículos 267 a 269 PCPC.

${ }^{77}$ Artículo 273 PCPC.

${ }^{78}$ Artículo 274 PCPC.

${ }^{79}$ Artículo 275 PCPC.

${ }^{80}$ Artículo 276 PCPC.

${ }^{81}$ Artículo 277 PCPC.

${ }^{82}$ Históricamente esta posibilidad de origen canónico estaba reservado para aque-
} 
Afortunadamente, el texto normativo lo deja como una potestad que quede a criterio del tribunal, es decir, el órgano jurisdiccional manejará esta circunstancia a su discreción y, entendemos, que lo más cauto será observar la verosimilitud de los hechos y los documentos, también, en relación a otros elementos que pudieran ayudar a generar la convicción ${ }^{83}$. Por otra parte, atendido el contenido del 1698 CC., en el caso de que el juez tenga dudas, no le bastará al demandante con la mera afirmación, sino que deberá probar la obligación o su extinción por uno de los medios oportunos, probablemente documentos tratándose del proceso civil.

Quisiéramos detenernos, en este punto, en el uso que dice relación con el enunciado legal al emplear el término "silencio". La carga que recae en el demandado supone que sus afirmaciones han de ser categóricas y precisas, también señala la norma que las afirmaciones ambiguas o evasivas podrán ser apreciadas por el tribunal como una forma de admisión tácita. Y hasta aquí nos parece razonable puesto que es deseable que el demandado participe y se defienda siempre que, con justa razón, pudiera hacerlo. Sin embargo, no alcanzamos a comprender la expresión "Su silencio [...] podrán ser consideradas por el tribunal como admisión tácita de los hechos [...]".

El silencio en la contestación de la demanda equivale a otra figura que se regula anteriormente (artículo 264 PCPC.) que es la rebeldía. De este modo, genéricamente en la contestación no puede haber silencio. Aunque en estricto rigor por escrito nunca pudiéramos hacer ruido y siempre estaríamos en silencio ${ }^{84}$. Pero comprendiendo que silencio se corresponde a toda acción igual a no hacer nada, en ningún caso podríamos hablar de silencio

llas cuestiones contractuales dentro del ámbito de las atribuciones de la Iglesia en la que no se exigía una voluntad expresa en atención al interés superior de la Iglesia. Así, varios son los ejemplos en que esto sucedía como el supuesto en que el esclavo deseaba ordenación sacramental, la hija que ingresa a la religión o el caso del marido y la mujer en relación a la profesión religiosa. En este tipo de supuestos en que existe un beneficio para la comunidad religiosa en su conjunto se "rebaja" el grado de consentimiento bastando no oponerse y guardar una actitud silenciosa. En este sentido, MAGNI, Cesare, cit. (n. 45), p. 58.

${ }^{83}$ Del mismo modo se está entendiendo en sede laboral donde, eso sí, la norma parece más clara. Así, resulta esclarecedora la sentencia de la Corte de Apelaciones de Santiago, de 20 de noviembre de 2011, rol No No 273-11: "Por otra parte, es posible concluir que la facultad de tener por tácitamente admitidos los hechos señalados por el actor en su demanda, tratándose precisamente de una facultad, puede legitimamente no ser ejercida por el sentenciador en la medida que no se haya formado convicción de la procedencia de tener por admitidos los hechos referidos, cuando de los antecedentes acompañados o tenidos a la vista no se desprenda la efectividad de los mismos, situación ante la cual siempre podrá establecer la existencia de hechos sustanciales, pertinentes y controvertidos".

${ }^{84}$ La Real Academia Española reconoce escribir como ausencia de silencio. 
en la contestación de la demanda si esta se presenta oportunamente y en la forma prescrita por el Proyecto.

Observemos, entonces a qué se refiere el Proyecto con este silencio y qué consecuencias derivan de su adopción como postura procesal. En primer lugar, sostenemos que genéricamente no se puede guardar silencio si se contesta $^{85}$. Si aceptamos esta premisa como válida, nos conduce a plantear dos posibles soluciones, ya que no creemos en un error en la redacción de la norma ${ }^{86}$. Por una parte, se debe entender el silencio como parcial y, por otra, no es más que una forma de reforzar el contenido de "afirmaciones ambiguas o evasivas".

Entonces, lo más probable es que esta redacción abierta a la interpretación estuviera buscando enfatizar el alcance total de la carga de controvertir los hechos y documentos de la contraria. Así, una correcta lectura del precepto nos llevaría a afirmar que lo que subyace bajo el espíritu de la norma es señalar que el silencio parcial, es decir, el silencio respecto de alguno de los hechos y documentos acompañados por el demandante pudieran acarrear la negativa consecuencia, para el demandado, de tener por reconocidos esos hechos o documentos ${ }^{87}$.

${ }^{85}$ Así la Corte Suprema siempre ha entendido que el silencio implica la declaración de rebeldía, en tanto no se realiza una conducta positiva de defensa. Por ejemplo, sentencia Corte Suprema, de 23 de enero de 2008, rol No o 5255-07: "En efecto, es jurisprudencia reiterada de este tribunal, que "el silencio del rebelde no importa acatamiento de la acción deducida en su contra, salvo disposición expresa que asi lo ordene”. Lo anterior es corolario de la vigencia, en nuestro sistema jurídico y particularmente para el tópico sub lite, de las normas que regulan la actividad probatoria de los litigantes, para la fijación de los hechos en que fundan sus asertos y peticiones"

${ }^{86}$ Menos cuando en el orden laboral se introdujo como medio de agilizar las actitudes del demandado. Walter Díaz, Rodolfo - Lanata Fuenzalida, Gabriela, Régimen legal del nuevo proceso laboral chileno (Santiago, LegalPublishing, 2009), p. 204: "La norma establece una sanción y no se refiere en forma concreta al evento de que el demandado no conteste, pero concurra a la audiencia, lo que podrá originar más de algún problema, pero estimamos que igual resulta aplicable a esta situación, pues parece ser que para eximirse de los defectos que la norma señala, debe negar en forma expresa. $\mathrm{Al}$ no contestar, no está negando, por lo cual cobraría aplicación la norma. De todas formas, se trata de una facultad para el juez, que siempre deberá ejercer de conformidad a las reglas de la sana crítica".

${ }^{87}$ Se produciría, en otras palabras una aplicación del principio de adquisición procesal. Lo explica diáfanamente, en sede de prueba, PALOMo VÉLEZ, Diego, cit. (n. 36), p. 203: “Tratándose de la confesión judicial espontánea expresa se aplica este principio. Las partes pueden, sin tener voluntad de favorecer a la contraria, reconocer la existencia de hechos que, en definitiva, las perjudican. Esto se puede dar en la exposición de los hechos que se recogen en la demanda o en la contestación de la demanda, ya que sientan su existencia con eventuales consecuencias en su perjuicio". 
Efectivamente, la forma de actuación y omisión de actuaciones de las partes determina inexorablemente que el juez extraiga indicios susceptibles de fundar una presunción ${ }^{88}$. Además, como bien explica Picó i Junoy la conducta de la parte puede acarrear la aplicación de la ficta admissio y nombra como ejemplo: "En la contestación a la demanda cuando el demandado no se pronuncie respecto de los hechos alegados por el actor en su demanda oformule respuestas evasivas, siempre que tales hechos le sean perjudiciales (art. 405.2. LEC)" $"$.

Si atendemos, además, a lo que ha sucedido en el proceso laboral, pareciera estar apostándose por un "quien calla otorga". Efectivamente la norma contemplada en el artículo 453 del Código del Trabajo parece apuntar en esa dirección y la jurisprudencia, también lo ha entendido en ese tenor. Así, por ejemplo, la Corte de Apelaciones de Santiago en sentencia de fecha 4 de noviembre (rol N $\mathrm{N}^{\circ} 1000-13$ ) ha señalado diáfanamente: "Resulta indiscutible que la aceptación tácita de los hechos que sirven de fundamento a la demanda, importa un reconocimiento o allanamiento a los mismos, por lo que no puede estimarse que respecto de ellos exista controversia y, por consiguiente, es improcedente la rendición de pruebas a su respecto. Por otra parte, si la audiencia de juicio tiene como propósito el rendir las pruebas que el juez requiera para dictar su sentencia, resulta de toda lógica entender que ella es innecesaria cuando tales pruebas no existirán, por lo que la dictación del fallo no puede retardarse. Aceptar las alegaciones del recurrente, implicaria la dilación innecesaria del procedimiento en perjuicio del demandante, lo que no resulta admisible, por lo que la petición de nulidad debe ser desestimada"90.

${ }^{88}$ Para un magistral tratamiento de los indicios endoprocesales, véase MUÑoz SABATÉ, Lluís, Fundamentos de prueba judicial civil. LEC 1/2000 (Barcelona, Bosch, 2001), pp. 418-420.

${ }^{89}$ Picó I Junoy, Joan, La buena fe procesal (Buenos Aires, Ibáñez, 2011), pp. 120 y 121. Continúa el autor señalando: "En esta línea la STS de 16 de mayo de 2008 destaca que la falta de explicación en la contestación a la demanda sobre los hechos relatados por el actor puede considerarse un síntoma de mala fe procesal. Así, ante una contestación que se limita a descalificar los hechos de la demanda sin concretar en que consiste la disconformidad del demandado, afirma: '[...] como señala el juzgador "a quo", la parte apelada (Sr. Jose Augusto) 'no dice ni concreta que información le falta', en el recurso de casación tampoco se expresa nada al respecto. Insistir en una actividad de mera descalificación sin dar razón alguna que explique la supuesta deficiencia informativa, constituye un comportamiento procesal inadmisible y rayana en mala de procesal".

${ }^{90}$ Podríamos, además, añadir que esa aceptación tácita de los hechos afirmados en la demanda no permiten al juzgador diferenciar cuáles admite y cuáles no, ya que al no hacerlo la ley, tampoco le corresponde realizar esa tarea al órgano jurisdiccional. Así, sentencia de la Corte de Apelaciones de Santiago, de 20 de noviembre de 2011, rol $\mathrm{N}^{\circ} \mathrm{N}^{\circ}$ 273-11: "no permite que el sentenciador distinga entre los hechos alegados por el actor, cuáles tiene por tácitamente admitidos y cuáles no, ya que el legislador no realiza 
Lamentablemente, esto solo es una interpretación posible. Pero se abren otras, sin necesidad de ser majaderos y buscar más allá de lo que se estipula. En primer término porque el Proyecto no hace ninguna referencia expresa a ese concepto de silencio parcial ${ }^{91} \mathrm{y}$, además, porque si atendemos a lo que señala el "Mensaje" todavía se nos generan más dudas ya que literalmente expone: "el demandado, junto con contestar la demanda, y de ofrecer y señalar su prueba en los mismos términos antes referidos, deberá controvertir los hechos afirmados por el actor y los documentos acompañados por éste, en forma categórica, bajo eventual sanción consistente en que el Juez podrá tenerlos como no admitidos". De este modo, no se asoma, por ninguna parte, el concepto de silencio parcial $y$, muy por el contrario, el Mensaje entrega una visión contradictoria con lo que el artículo 272 PCPC. establece, ya que antepone una negación al concepto admisión que cambia radicalmente el sentido de la norma.

Sin embargo, nos decantamos por postular que, en realidad y aunque parece un error de imprenta, no debería modificar sustancialmente el sentido. Lo mismo debería significar que el juez pueda tenerlos como admitidos, que el juez pueda tenerlos como no admitidos, ya que no deja de ser más que una potestad del juez que podemos reducir a un cincuenta por ciento de posibilidades, de que se adopte una u otra postura.

Por lo tanto, no pareciera tan exagerado tratar de averiguar qué es lo que se prescribe y que aunque en una primera lectura parezca tan diáfano, observamos que es un complejo enunciado que puede llevar al juzgador a tener que realizar interpretaciones del mismo. Y ese es precisamente el problema, que ante la necesidad de interpretación puede venir la desigualdad e indefensión para las partes.

Así pues, una de las interpretaciones plausibles que un órgano jurisdiccional puede hacer es que silencio equivale a rebeldía ${ }^{92}$. En todo caso, esto sería la condición más beneficiosa para el demandado. Ya que si lo observamos bien, estratégicamente es mejor no contestar que hacerlo mal. Efectivamente, el Proyecto, al regular la inactividad del demandado, señala que la incomparecencia oportuna del demandado acarreará la negación genérica de los hechos

distinción alguna y no existen otros elementos en la causa que sirvan de fundamento para hacer algún distingo".

${ }^{91} \mathrm{Si}$ bien es cierto que en legislaciones comparadas, como la española, no se habla de silencio parcial, no lo es menos que también se señalan consecuencias a la no negación categórica de todos los hechos. Por todos, Montero Aroca, Juan, cit. (n. 41), p. 213: "pero cuando el demandado contesta a la demanda la no negación expresa de los hechos puede ser considerada por el juez como admisión implícita y, aún más, las respuestas evasivas pueden ser estimadas por el tribunal en la sentencia como admisión (Artículo 405.2 LEC)”.

${ }^{92}$ Difícilmente un tribunal señalará que se trata de rebeldía. Afortunadamente se encuentra regulada en forma expresa en el artículo 264 PCPC. 
y la imposibilidad de reunir prueba, salvo que pudiera hacerlo acogiéndose a lo dispuesto en el art. 276 PCPC. Indiscutiblemente, entonces, se prevé una consecuencia más beneficiosa, ya que el demandado contumaz negará todos los hechos, por la sola circunstancia de no comparecer, mientras que si comparece deberá negar categóricamente todos y cada uno de los hechos sin poder olvidar ninguno.

Indudablemente, esta situación lleva a plantearnos el dilema sobre qué es mejor, contestar o no contestar. Ya que si por descuido, falta de planificación, o, simplemente, porque el demandado considera que algunos de los dichos del actor no son relevantes y, por lo tanto, no ameritan de su negación, el tribunal puede dar (o no) por admitidos tácitamente algunos hechos o documentos fundados en el silencio. Al contrario, el mantener una actitud más pasiva, acarrea el beneficio de no caer en ese riesgo e inmediatamente darse por negados todos los hechos y documentos que, en ningún caso se relevarán de prueba.

Entonces, ¿cuál es la desventaja? Teóricamente, el que no contesta la demanda deberá soportar la consecuencia de darse por evacuado ese trámite y, por lo tanto, perdería su derecho a proponer prueba ${ }^{93}$. Sin embargo, como reconoce el art. 276 PCPC., podrá en la audiencia preliminar realizar las alegaciones que considere oportunas respecto a los dichos de la demandante y además, el tribunal tiene la obligación de conceder a la contraparte "la oportunidad para ejercer sus facultades de contradicción y prueb a correspondientes" motivo por el que el Juez pudiera alzar "el castigo" de no proponer prueba, en atención a la necesaria igualdad de oportunidades que inspira todo el nuevo proceso civil (artículo 4 PCPC.) ${ }^{94}$.

Otra enseñanza posible ante esta tesitura es que si tomamos la opción de contestar y aseguramos, de este modo, la posibilidad de controvertir los hechos y de proponer todas las pruebas que consideremos oportunas, más allá de la discrecionalidad del juez, deberíamos comenzar negando categórica y precisamente la veracidad de todos los hechos alegados en la demanda. Quizá pudiera ser hasta recomendable utilizar esta fórmula ${ }^{95}$ a modo de

${ }^{93} \mathrm{El}$ artículo 264 PCPC. establece: "no podrá rendir prueba en juicio". Sin embargo, inmediatamente añade "salvo en la forma y condiciones previstas en el artículo 276 ".

${ }^{94}$ Esta posibilidad solo se podría dar en el supuesto de que el juez tenga dudas sobre la decisión final y, por lo tanto, estime necesario recibir la causa a prueba. En caso contrario, sucederá lo señalado en la sentencia de la Corte de Apelaciones de Talca, de 9 de diciembre de 2010, rol N No 224-2010:"dando por concluida la audiencia y procediendo a dictar la respectiva sentencia definitiva, estimando como tácitamente admitidos los hechos de la denuncia por considerar que no existian hechos sustanciales, pertinentes $y$ controvertidos".

${ }^{95}$ Esto nos recuerda mucho a la situación de las legis actiones romanas (primer procedimiento que se establece en Roma) en que el demandante señalaba que tenía un de- 
encabezar un escrito de contestación, ya que de lo contrario, tomaremos el riesgo de que el tribunal considere que hemos guardado silencio y dé por admitidos hechos o pruebas sin necesidad de su demostración o rendición en la audiencia de juicio. Si bien es cierto, que esta obligación es actualmente trasladable, a tenor de lo dispuesto en el artículo 313 PCPC., no lo es menos que la redacción del nuevo precepto parece imponer un estándar más alto de contradicción y que, además, puede tener una consecuencia más gravosa en tanto que la etapa de proposición probatoria se adelanta y determina la posibilidad de admitir como ciertos algunos documentos sin necesidad de discutir su alcance en la audiencia de juicio.

\section{IGUALDAD DE OPORTUNIDADES: \\ EL DEMANDANTE TAMBIÉN PUEDE OTORGAR CON SU SILENCIO}

El Proyecto, pese a despertar nuestra confusión en la contestación a la demanda, podemos decir que es justo si entendemos por justicia dar a todos los mismo ${ }^{96}$. Efectivamente, una vez contestada la demanda se le va a dar traslado al demandante para que, hasta cinco días antes de la audiencia preliminar, se pronuncie categórica y precisamente sobre la autenticidad, integridad y validez de los documentos acompañados por el demandado ${ }^{97}$.

Una vez más, el Proyecto habla de silencio. Y, por lo que podemos observar, en este caso silencio tiene otro significado, siendo que apretantemente se trata del mismo trámite pero para el demandante. No es el mismo trámite porque no habla sobre hechos, solo documentos. No estaríamos ante rebeldía porque ya se encuentra personado; solamente es estrategia defensiva; y sí puede guardar silencio no haciendo nada; en el otro supuesto o es rebelde, o no guarda silencio, o el silencio es parcial, pero la ley no lo distingue.

recho y solicitaba al demandado que lo afirmara o lo negara. De este modo, se buscaba una respuesta categórica antes de iniciar propiamente el juicio. Resulta muy interesante en este sentido, BERnARD MAINAR, Rafael, Curso de derecho privado romano (Caracas, Universidad Católica Andrés Bello, 2006), p. 212.

${ }^{96}$ Hunter Ampuero, Iván, La iniciativa probatoria del juez y la igualdad de armas en el proceso civil, en Ius et Praxis, 17 (2011) 2, p. 54.

${ }^{97}$ Artículo 274: “Carga de controvertir los documentos acompañados por el demandado y su sanción. El demandante deberá pronunciarse categórica y precisamente, hasta cinco días antes de la audiencia preliminar, sobre la autenticidad, integridad y validez de los documentos que en la contestación se hubieren acompañado./ Su silencio, asi como sus afirmaciones ambiguas o evasivas en la contestación podrán ser consideradas por el tribunal como admisión tácita de los hechos que le sean perjudiciales, así como admisión de la autenticidad, integridad y validez de los documentos acompañados". 


\section{ConClusión}

Quien calla otorga y quien calla no otorga. Efectivamente, como hemos podido observar la ausencia de actividad procesal, el silencio, determina en varias instancias la aceptación tácita de los dichos (hechos y documentos) de la contraria. A su vez, el silencio más absoluto reflejado en la ausencia total de actividad procesal, que conduce a la declaración de rebeldía, propone la consecuencia de no otorgar al considerarse que se niegan todos los hechos y documentos aportados por la contraria.

Es importante remarcar que el silencio absoluto lleva aparejada una condición más ventajosa en tanto que la rebeldía, haciendo caso de la tradición jurídica más longeva, determina un principio de defensa general que obliga al demandante a emplear toda su estrategia como si estuviera litigando contra alguien que opone resistencia a todos sus dichos.

Por lo tanto, nos encontramos con los dos principios consagrados en nuestro ordenamiento y en la reforma del mismo. Hay que tener en cuenta que este principio queda potestativamente entregado al juez quien interpretando el futuro proyecto podrá entender una cosa u otra en función del grado de certidumbre y convicción que la afirmación de una parte y el silencio de otra, generen en su convicción.

Resulta, eso sí, bien prudente resaltar esa potestad en el contexto de la reforma y del nuevo rol activo del juez. Actualmente, quizá no se está realizando una lectura tan ajustada a nuestra hipótesis, pero señales como la que nos entrega la jurisdicción laboral y el nuevo papel del juez civil deben conducirnos a reflexionar sobre la importancia de una ágil y concienzuda defensa que permita que la parte vencedora lo resulte por su razón y no por la consecuencia jurídica derivada de su inactividad.

Finalmente, debemos realizar un replanteamiento a la hora de escribir las lecciones sobre Derecho procesal para distinguir, a lo menos, dos grandes efectos que produce el silencio en la actividad defensiva del demandado. De una parte, el que calla puede estar aceptando los hechos y documentos de la contraria cuando al tratar de desvirtuarlos no lo haga con categórico esfuerzo y, por otra, el que calla absolutamente y no se defiende generará con su contumacia una negación que alcanzará a todos y cada uno de los dichos y material probatorio de la parte demandante.

\section{BiBLIOGRAFÍA}

Almagro Nosete, José, Derecho procesal (Valencia, Tirant lo Blanch, 1992). Alvarado Velloso, Adolfo, Introducción al estudio del derecho procesal (Buenos Aires, Editorial Rubinzal, 2000). I. 
Anabalón Sanderson, Carlos, Tratado práctico de derecho procesal civil (Santiago, Librotécnia, 1966), II.

ARA, Carmen, La tutela del rebelde en el proceso civil (Barcelona, Bosch, 1993).

Benavente, Darío, Derecho procesal. Juicio ordinario. Recursos procesales (Santiago, Editorial Jurídica de Chile, 1991).

Bernard Mainar, Rafael, Curso de derecho privado romano (Caracas, Universidad Católica Andrés Bello, 2006).

BetTr, Emilio, Declarazione voluntaria nella dogmatica bizantina, en Studi in memoria di E. Albertario (Milano, Giuffrè, 1953), II.

Bordalí Salamanca, Andrés - Cortez Marcovich, Gonzalo - Palomo Vélez, Diego, Proceso civil. El juicio ordinario de mayor cuantía (Santiago, Abeledo Perrot - Thompson Reuters, 2013).

Carocca Pérez, Manual de derecho procesal, II: Los procesos declarativos (Santiago, LexisNexis, 2003).

CARrasco Poblete, Jaime, La rebeldía en los procesos civily laboral (Santiago, Abeledo Perrot -LegalPublishing, 2010).

Carretta Muñoz, Francesco, Deberesprocesales de laspartes en el proceso civil chileno: referencia a la buena fe procesal y al deber de coherencia, en Revista de Derecho de la Universidad Austral de Chile, 21 (2008) 1.

Casarino Viterbo, Mario, Manual de derecho procesal. Derecho procesal civil. El proceso en general o reglas comunes a todo procedimiento (Santiago, Editorial Jurídica de Chile, 2009), III.

Correa Selame, Jorge, Curso de derecho procesal (Santiago, Ediciones Jurídicas de Santiago, 2006), III

Cortés Domínguez, Valentín - Moreno Catena, Víctor, Derecho procesal civil. Parte general (Valencia, Tirant lo Blanch, 2010).

Couture, Eduardo, Fundamentos de derecho procesal civil (Buenos Aires, Depalma, 1958).

Devis Echandía, Bernardo, Compendio de pruebas judiciales (Bogotá, Temis, 1969).

Figueroa Yávar, Juan Agustín - Morgado San Martín, Erika, Jurisdicción, competencia y disposiciones comunes a todo procedimiento (Santiago, LegalPublishing - Thompson Reuters, 2013).

González, Atilio Carlos, Silencio y rebeldia en el proceso civil (Buenos Aires, Astrea, 1995).

Hunter Ampuero, Iván, La iniciativa probatoria del juez y la igualdad de armas en el proceso civil, en Ius et Praxis, 17 (2011) 2.

Hunter Ampuero, Iván, Roly poderes del juez civil: Una mirada desde la eficiencia del proceso, en Revista de Derecho Universidad Católica del Norte, 18 (2011) 2.

JorQuera LorCa, René, Sintesis de derecho procesal civil (Santiago, Ediciones Jurídicas La Ley, 1995).

Magni, Cesare, Il silenzio nel diritto canonico, en Rivista di Diritto Privado (1934) 1.

MAGRO SERVET, Vicente, Los hechos nuevos o de nueva noticia y las alegaciones complementarias en la LEC, en La Ley 7139 (2009) 1.

Marinoni, Luiz, Novas linhas do processo civil (Sao Paulo, Malheiros, 2000).

Montero Aroca, Juan, Derecho jurisdiccional, II: Proceso civil. (Valencia, Tirant lo Blanch, 2013).

Muñoz Sabaté, Lluís, Fundamentos de prueba judicial civil. LEC 1/2000 (Barcelona, Bosch, 2001). 
Orellana Torres, Fernando - Pérez Ragone, Álvaro, Radiografía de la rebeldía en el proceso civil: Tópicos hacia una adecuada regulación de la nueva justicia civil, en Ius et Praxis, 13 (2007) 2.

Orellana Torres, Fernando, Manual de derecho procesal. Procedimientos civiles ordinarios y especiales (Santiago, Librotecnia, 2006).

Ortells Ramos, Manuel, Derecho procesal civil (Cizur Menor, Thompson Aranzadi, 2007).

PALOMo Vélez, Diego, La audiencia previa y el modelo procesal civil oral: consideraciones en torno a una pieza procesal clave, en De la Oliva, Andrés - Palomo Vélez, Diego, Proceso civil. Hacia una nueva justicia civil (Santiago, Editorial Jurídica de Chile, 2007).

PAlomo Vélez, Diego, Las cargas probatorias dinámicas: ¿Es indispensable darse toda esa vuelta?, en Ius et Praxis, 19 (2013) 2.

Picó I Junoy, Joan, La buena fe procesal (Buenos Aires, Ibáñez, 2011).

PRÜTTING, Hans, Carga de la prueba y estándar probatorio: La influencia de Rosenberg y Karl Hainz Schwab para el desarrollo del moderno derecho probatorio, en Ius et Praxis, 16 (2010) 1.

Ramos Méndez, Francisco, Derecho procesal civil (Barcelona, Bosch, 1985), I.

Rodríguez GarcÉs, Sergio, Derecho procesal funcional (Santiago, Vitacura, 1993).

Rodríguez PAPIC, Ignacio, Procedimiento civil. Juicio ordinario de mayor cuantía (Santiago, Editorial Jurídica de Chile, 2012).

Ruay Sáez, Francisco Alberto, Análisis critico sobre la inclusión del principio de buena fe procesal en el "Proyecto de Código Procesal Civil" chileno, en Revista de Derecho y Ciencia Politica, 4 (2013) 3.

Salas Astrain, Jaime Iván, Nuevo derecho procesal (Santiago, El Jurista Ediciones Jurídicas, 2010).

Schulz, Fritz, Principles of Roman Law, (Oxford, Oxford University Press, 1956).

Souza, Artur, Contraditório e revelia. Perspectiva critica dos efeitos da revelia em face da naturaleza dialética do proceso, en Revista dos Tribunais (2003) 1.

ToмÁs, Gema, Fuentes jurídicas del principio "qui tacet, consintere videtur". Realidad juridica versus difusión social, en Revue Internationale des Droits de l'Antiquité, 3 (2003).

Walter Díaz, Rodolfo - Lanata Fuenzalida, Gabriela, Régimen legal del nuevo proceso laboral chileno (Santiago, LegalPublishing, 2009). 